\title{
GRAFITE E POÉTICAS COMPARTILHADAS NO PÁTIO HUMANIDADES DA UFG
}

\author{
Eliane Maria Chaud ${ }^{1}$, Marcos Antônio Soares ${ }^{2}$
}

\begin{abstract}
Resumo: Este artigo discorre sobre uma experiência em arte com grafite, realizada no Pátio Humanidades da Universidade Federal de Goiás (UFG), a qual teve a participação de estudantes e egressos do curso de Artes Visuais da Faculdade de Artes Visuais da UFG e artistas moradores do bairro Itatiaia, Goiânia, circunvizinho à universidade. $\mathrm{O}$ texto reflete determinadas questões conceituais sobre o grafite $\mathrm{e}$ as relações com o projeto de pesquisa e extensão "Por uma poética compartilhada: artes e atos goianos", em andamento, que tem entre seus objetivos favorecer a troca de experiências e a formação no âmbito artístico de residentes na comunidade do entorno da UFG. Apresenta os artistas e descreve a contribuição e a percepção destes na realização da referida ação artística, a qual, avaliada positivamente, favoreceu a possibilidade de um novo pensar e vivenciar naquele espaço da universidade.
\end{abstract}

Palavras-chave: Grafite. Poética compartilhada. Universidade e comunidade.

GRAFFITI AND SHARED POETICS IN THE PATIO HUMANIDADES OF UFG

\begin{abstract}
This article discusses the experiences of graffiti, held in the Patio Humanidades of the Federal University of Goiás (UFG), which had the participation from students and graduates from the Visual Arts course of the Visual Arts Faculty of UFG and surrounding neighborhood artists from Itatiaia, Goiânia, near the university. The text reflects certain conceptual questions about graffiti, its relations with the research project and extension "For a shared poetics: arts and acts of Goianos", in progress, that has among its objectives to favor and exchange the experiences and the formation in the artistic scope of residents of the UFG community. It presents the
\end{abstract}

1 FAV/UFG - elianechaud@gmail.com

2 FAV/UFG - marcossoares.ufg@gmail.com 
artists and describes their contribution and perception in the accomplishment of the mentioned artistic action, which, was evaluated positively, favoring the possibility to a new way of thinking and experiencing it in that space of the university.

Key words: Graffiti. Shared poetics. University and community.

GRAFITI Y POÉTICAS COMPARTIDAS EN EL PATIO HUMANIDADES DE LA UFG

Resumen: Este artículo discurre sobre una experiencia en arte con grafiti, realizada en el Patio Humanidades de la Universidad Federal de Goiás (UFG), la cual tuvo participación de estudiantes y egresados del curso de Artes Visuales de la Facultad de Artes Visuales de la UFG y artistas habitantes del barrio Itatiaia, Goiânia, vecino a la universidad. El texto refleja determinadas cuestiones conceptuales sobre el grafiti y las relaciones con el proyecto de investigación y extensión "Por una poética compartida: artes y actos goianos", en curso, que tiene entre sus objetivos favorecer el intercambio de experiencias y la formación en el ámbito artístico de habitantes de la comunidad en torno a la UFG. Presenta a los artistas y describe la contribución y la percepción de ellos en la realización de la referida acción artística, la cual, evaluada positivamente, favoreció la posibilidad de un nuevo pensar y vivenciar en aquel espacio de la universidad.

Palabras clave: Grafiti. Poética compartida. Universidad y comunidad.

\section{INTRODUÇÃO}

Caminhando pelas cidades, é comum depararmo-nos com uma diversidade incrível de manifestações e referências visuais, dentre essas, o grafite. Como uma manifestação artística contemporânea, em geral, o grafite não é mais visto como um ato ilegal ou vandalismo. A sua presença nos ambientes públicos, tanto internos e como externos, muitas vezes exerce em nós uma reação significativa, provocativa, reflexiva e crítica. Tais fatores determinam, em importantes e amplos meios culturais, um crescente reconhecimento da importância do grafite em vários projetos e contextos socioculturais.

Alguns aspectos dessa produção chama-nos a atenção: i. atualmente, o maior grafite do mundo está situado no Brasil, o mesmo foi executado no Rio de Janeiro, no espaço destinado aos jogos olímpicos de 2016, realizado pelo grafiteiro Eduardo Kobra, denominado de Mural "Etnias", possuindo a 
dimensão de 15 metros de altura e 170 metros de comprimento; ii. mediante as imagens que circulam pela internet, tem havido uma intensa divulgação e visibilidade das pessoas às produções em grafite realizadas em todo o mundo, o que tem favorecido a troca de experiências, o conhecimento de novas propostas e a idealização de projetos cada vez mais ousados e inseridos na vida social; iii. além de ocupar os espaços públicos, muitas vezes, situando-se em ambientes de maior visibilidade ou lugares inusitados das cidades, o grafite também está presente nos museus e leilões de arte, é assunto de capa em revistas populares e especializadas, destacando-se, inclusive, como referência visual na publicidade e em objetos sofisticados do design.

Com a socialização do grafite nas últimas décadas, constata-se uma mudança em relação ao significado e à ocupação dos espaços urbanos, assim como, uma atitude viável de democratização e ampliação do acesso das pessoas à determinadas produções artísticas. Sobre esse aspecto, o grafiteiro britânico Banksy (2012), um dos artistas mais conhecido na atualidade, assim afirma:

Ao contrário do que dizem por aí, o grafite não é a mais baixa forma de arte. Embora seja necessário se esgueirar pela noite e mentir para a mãe, grafitar é, na verdade, uma das mais honestas formas de arte disponível. Não existe elitismo ou badalação, o grafite fica exposto nos melhores muros e paredes que a cidade tem a oferecer e ninguém fica fora por causa do preço do ingresso. (BANKSY, 2012, p. 8)

Essa condição que caracteriza o grafite como uma produção cultural para diferentes níveis sociais, de natureza pública e com modos diferenciados de se fazer e pensar arte, um modus operandi que amplia o conceito artístico, é o que motiva-nos realizar determinadas ações colaborativas entre a universidade e a comunidade, como as que vêm ocorrendo no projeto "Por uma poética compartilhada: artes e atos goianos". Considerando a relevância dessas ações, neste artigo trataremos de alguns aspectos teóricos e processuais relacionados com a produção em grafite desenvolvida no Pátio Humanidades da Universidade Federal de Goiás (UFG), mediante a atuação de estudantes e egressos do curso de Artes Visuais, vinculados à Faculdade de Artes Visuais (FAV) da UFG, e artistas moradores do bairro Itatiaia, Goiânia, circunvizinho à universidade. 


\section{AsPeCTOS DO PROJETO}

As ações participativas na atividade de vitalização do Pátio Humanidades da UFG estão relacionadas com o projeto de extensão e pesquisa "Por uma poética compartilhada: artes e atos goianos", que foi cadastrado e encontra-se em andamento desde 2013, sob a coordenação da professora Eliane Maria Chaud, da FAV/UFG. Este projeto tem como objetivo desenvolver ações de formação em Artes Visuais e criar particularidades de aproximações entre as comunidades dos bairros adjacentes ao Campus Samambaia da UFG. Compreendendo a arte como lugar de interações e relações intersociais, as ações desenvolvidas no projeto visam criar aproximações entre universidade e comunidade, em particular, trazer a comunidade para participar das atividades artísticas desenvolvidas pela FAV e/ou outras unidades e órgãos da UFG.

A afinidade de objetivos do projeto "Por uma poética compartilhada: artes e atos goianos" com o programa Topofilias - coordenado pela professora Rusvênia Luiza B. R. Silva -, favoreceu a iniciativa de inserção e visibilidade da arte em espaços pouco frequentados da UFG, visando possibilitar a recuperação e/ou transformação destes lugares em ambiente de reconhecimento e pertencimento da comunidade universitária. A ação definida e realizada nessa etapa do projeto, em 2018, com a produção de grafite no Pátio Humanidades da UFG, contribuiu para intensificar essa aproximação entre a universidade e a comunidade, ao integrar em uma ação artística conjunta os graduandos e egressos de cursos da FAV e os artistas residentes no bairro Itatiaia, na cidade de Goiânia.

O termo "poéticas compartilhadas" refere-se às experiências de arte em contexto de comunidade. No caso específico de nosso projeto, o intuito é compartilhar saberes e afetos entre a comunidade de bairros adjacentes da UFG, em especial, o bairro Itatiaia, e os discentes e docentes da Faculdade de Artes Visuais da UFG, dando ênfase à "processos abertos de conversação". Busca-se proximidades com o outro, sobretudo, aqueles que se encontram tão perto à UFG, porém, distantes do ambiente universitário. Preocupamos também com o conhecimento e o contado desses sujeitos com a arte, assim como, a importância do reconhecimento das questões que fortaleçam o seu pertencimento no bairro, a consciência de ser e estar neste lugar. Propomos, por meio da arte, reflexões e conscientizações sobre as identificações e relações com o lugar onde vivem os participantes do projeto, fazendo destes interlocutores artísticos. Além disso, busca-se provocar e exercitar - entre os participantes e 
equipe do projeto - diferentes percepções sobre os espaços públicos do bairro e aproximações com o fazer artístico. Pretende-se que as ações do projeto sejam instauradoras de experiências e transformadoras de todos os indivíduos participantes do processo. Tais práticas artísticas, conforme entendimento de Bourriaud, possuem uma característica relacional: “[...] conjunto de práticas que toma como ponto de partida teórico e prático o grupo das relações humanas e seu contexto social, em vez de um espaço autônomo e privativo" (BOURRIAUD, 2009, p. 151).

Propor este tipo de ação compartilhada, demanda uma análise sobre o significado deste tipo de relação, de maneira a valorizar também a fala e a escuta do outro. Tendo por referência a artista Lygia Clark, nós, da universidade, somos "propositores" de ações para um coletivo em processo de vivência, construção, invenção e significação de suas práticas socioculturais, em particular, no campo estético e artístico (MILLIET, 1992).

\section{A UNIVERSIDADE COMO CONTEXTO DE AÇÃO ARTÍSTICA E RELAÇÃO} COM A COMUNIDADE

O início do projeto de arte em grafite no Pátio Humanidades da UFG, decorreu do convite encaminhado pela Reitoria da UFG, e, posteriormente, atendeu os objetivos do programa Topofilias. Nesse sentido, foi solicitado o desenvolvimento de uma proposta artística que pudesse contribuir com a vitalização do referido espaço, o qual estava, sobretudo, comprometido com problemas relacionados ao tráfico de drogas - uma situação que preocupava os gestores das unidades que circundam o pátio, os representantes estudantis e a gestão administrativa da UFG. Vale ressaltar o apoio dessas unidades, bem como da Reitoria e Pró-Reitoria de Extensão e Cultura da UFG, para a concretização do trabalho.

Quando chegamos no Pátio Humanidades, período de férias, em fevereiro de 2018, o espaço já se encontrava sem a problemática das drogas. As paredes dos prédios estavam pintadas e o ambiente limpo - uma situação bem diferente de meses anteriores. Após alguns contatos e conversas com um grupo de universitários da FAV e artistas da região, decidimos que seria importante desenvolvermos uma ação artística que pudesse dialogar de modo mais próximo com o público que frequenta aquele espaço. 
Avaliamos que por meio da linguagem do grafite poderíamos estabelecer relações de aproximação entre artistas e a comunidade universitária. O desafio era grande, e para tanto, contamos com um grupo qualificado, formado por: os artistas e estudantes do curso de bacharelado em Artes Visuais da FAV/ UFG, Verônica Oliveira Fernandes (Nika), Lucas Fernando Rodrigues de Souza (Lucas Caslú) e Renan Accioly Wanser; os artistas e egressos da FAV/UFG, Jhony Robson dos Santos (Bulacha) e Diogo Fernandes Honorato (Rustoff); e artistas convidados do bairro Itatiaia, Ismael Albertino da Mota Teles e Vladimir Martins da Silva (Pirandello). Com esse grupo, tivemos o intuito de atender os objetivos do projeto "Por uma poética compartilhada: artes e atos goianos", de criar aproximações e gerar relações entre UFG e comunidade, assim como, integrar artistas iniciantes e outros com um processo mais definido quanto ao seu trabalho artístico.

Durante a realização dos grafites no Pátio Humanidades, foram realizados registros fotográficos e entrevistas com os artistas, favorecendo uma documentação e compreensão desse rico processo criativo vivido na UFG. Parte destes relatos são apresentados no decorrer do texto.

Sabemos que a universidade se organiza além do ensino, realizando uma diversidade de atividades no âmbito da pesquisa e extensão. O projeto de grafite no Pátio Humanidades se aproxima dos objetivos da extensão da UFG, a qual propõe "organizar, apoiar e acompanhar ações que visem à interação da universidade com a sociedade, gerando benefícios para ambas", portanto, suas ações têm como objetivo propiciar aproximações da universidade com a comunidade. Assim, o projeto com grafite pautou-se no objetivo de desenvolver atividades conjuntas aos moradores do bairro Itatiaia, que ao mesmo tempo que se colocam tão próximos fisicamente, se apresentam um tanto distantes das atividades realizadas na universidade.

Dentre os princípios em que se pautou o projeto, demos atenção especial às diferenças, às singularidades e às individualidades dos sujeitos participantes do processo. Valorizando a condição de igualdade entre os participantes, sem o estabelecimento de hierarquias de saberes (FRADE, 2015), operamos a ação artística no Pátio Humanidades apoiando e reconhecendo o valor e o trabalho artístico de cada participante. Criamos um ambiente de interações, propicio ao diálogo, ao trabalho coletivo e à socialização de conhecimentos e aprendizagens, visando a condição para que cada um mostrasse as particularidades de seu trabalho da maneira como achasse oportuno. 


\section{SOBRE O GRAFITE}

Inerente ao campo estético-artístico, num sentido amplo, o grafite é uma linguagem visual com raízes culturais e históricas profundas. Desde os primórdios da humanidade os registros visuais fazem parte do cotidiano humano, sendo elaborados em diferentes suportes, lugares e culturas, conforme as particularidades e intencionalidades dos indivíduos e/ou grupos sociais. Entre as estratégias, as intencionalidades e os meios para sua sobrevivência, historicamente o ser humano vem construindo, reinventando e aprimorando possibilidades de sentir, valorizar, representar e significar o mundo em que se encontra situado. Assim como o alimento e outras necessidades vitais, necessitamos dos registros visuais para de/marcar a nossa concepção e presença no mundo social e material no qual fazemos parte.

No decorrer de uma longa jornada de experimentações, vivências e aprendizagens, temos utilizado de diferentes suportes e técnicas expressivas, como por exemplo, os registros gráficos e pictóricos nas superfícies de interiores de cavernas e rochas em abrigos, as inscrições em placas de argila e pedra, as composições visuais nos painéis de madeira e tecido, os grafismos em folhas de papel, as pinturas e tatuagens no corpo humano, as intervenções visuais em edifícios, muros e artefatos que compõem a paisagem urbana.

As concepções e histórias sobre o grafite são polêmicas e controversas (TAVARES, 2010; LONGMAN, 2017). É consenso que a sua presença nos contextos urbanos se intensificou e internacionalizou a partir da segunda metade do século XX, demarcando uma característica visual das grandes cidades, em diferentes regiões do mundo. No entanto, a ênfase das produções acadêmicas sobre a história do grafite em alguns países da Europa ou dos Estados Unidos - reiterando o olhar eurocêntrico que ainda paira sobre nós -, não significa afirmar a sua ausência na história de variadas culturas. Nesse sentido, como exemplo, merece reconhecimento as pinturas murais e os grafismos elaborados pelos povos antigos e atuais que vivem nas Américas, os grafites geométricos e figurativos produzidos por povos milenares da África, Ásia e Oceania, os quais, ainda, mantém viva as suas diversidades de tradições expressiva-visuais sobre diferentes temas e suportes.

Considerando as diversas possibilidades e intencionalidades que motivam a expressão humana, entendemos que qualquer manifestação gráfica em diferentes tipos de suportes e lugares - pode ser considerada autêntica 
e justificável, sobretudo, pelo/s indivíduo/s autor/es. Como uma linguagem pessoal e livre, em muitos casos, o grafite é meio de comunicação e expressão de presença, símbolo de ousadia e manifestação social, sendo frequente a sua realização sobre qualquer superfície que potencialize a mensagem no contexto urbano (KNAUSS, 2001). No entanto, essa mesma manifestação pode infringir ou interferir em certos objetos ou espaços instituídos por outros indivíduos ou coletividades - como monumentos, prédios públicos e privados, as ruas da cidade, entre outros - com o objetivo de ressignificar e/ou desconfigurar seu sentido, aparência e funcionalidade original. Em geral, essas intervenções visuais possuem particularidades, intencionalidades e conteúdos que confluem e/ou questionam a paisagem urbana. Como sintetiza Longman (2017), no contexto brasileiro o termo grafite possui um sentido mais amplo que o usual em outros países:

Este livro adota, como regra geral, a palavra grafite, forma aportuguesada de graffiti. Em inglês, ela é usada em um sentido mais estrito que em português, e se refere especificamente à prática que tem na assinatura do nome (tag/lettering) sua matriz fundamental. Em português, a palavra tem sentido mais abrangente, designando também o desenho figurativo no espaço público. É com esse caráter amplo que a adotamos aqui. Em inglês, usa-se a expressão street art ("arte de rua" ou "arte urbana") como expressão mais ampla, que inclui murais figurativos e técnicas que podem extrapolar o uso do spray, como stickers e lambe-lambes. No Brasil, existe ainda o "picho" ou "pichação", manifestação concentrada no texto, assim como o graffiti americano, mas com uma radicalidade de linguagem e de propósitos que lhe é própria.

Este livro não hierarquiza/seleciona/prioriza nenhuma dessas categorias. Procura, ao contrário, mostrar a convivência das diversas expressões na cidade, lembrando que as definições não são fechadas e que os termos se cruzam, se misturam e se confundem nas diferentes línguas, usos e contextos. (LONGMAN, 2017, s/p).

\section{OS PARTICIPANTES DO PROJETO}

Para realização do projeto foi imprescindível a participação ativa dos artistas, os quais demonstraram compromisso, responsabilidade, respeito e criatividade durante todo o processo de execução dos trabalhos no Pátio Humanidades da UFG. A partir de depoimentos levantados no decorrer do período de execução dos trabalhos, destacaremos alguns aspectos sobre as 
concepções de grafite e os principais determinantes que influíram na formação artística dos participantes no projeto:

\section{Verônica Oliveira Fernandes (Nika)}

Verônica, chamada de Nika, estudante do curso de Artes Visuais - Bacharelado, desde o início do curso já manifestava o seu interesse em trabalhar o grafite como expressão. É exemplar o fato, ocorrido na disciplina "Introdução ao Tridimensional", ministrada no $1^{\circ}$ período da graduação, onde apresentou um trabalho conceitual utilizando-se de uma lata de tinta spray. A artista grafitou temas relacionados com universo da mulher (Figura 1), com ênfase para cores e formas geométricas e a representação figurativa do corpo feminino. Mesmo sendo uma iniciante no campo da arte em grafite, ela se colocou seriamente no processo, demonstrando garra, desejo e potencialidade neste fazer.

Ficura 1 - Fotografia do trabalho de grafite de Nika no Pátio Humanidades/UFG.

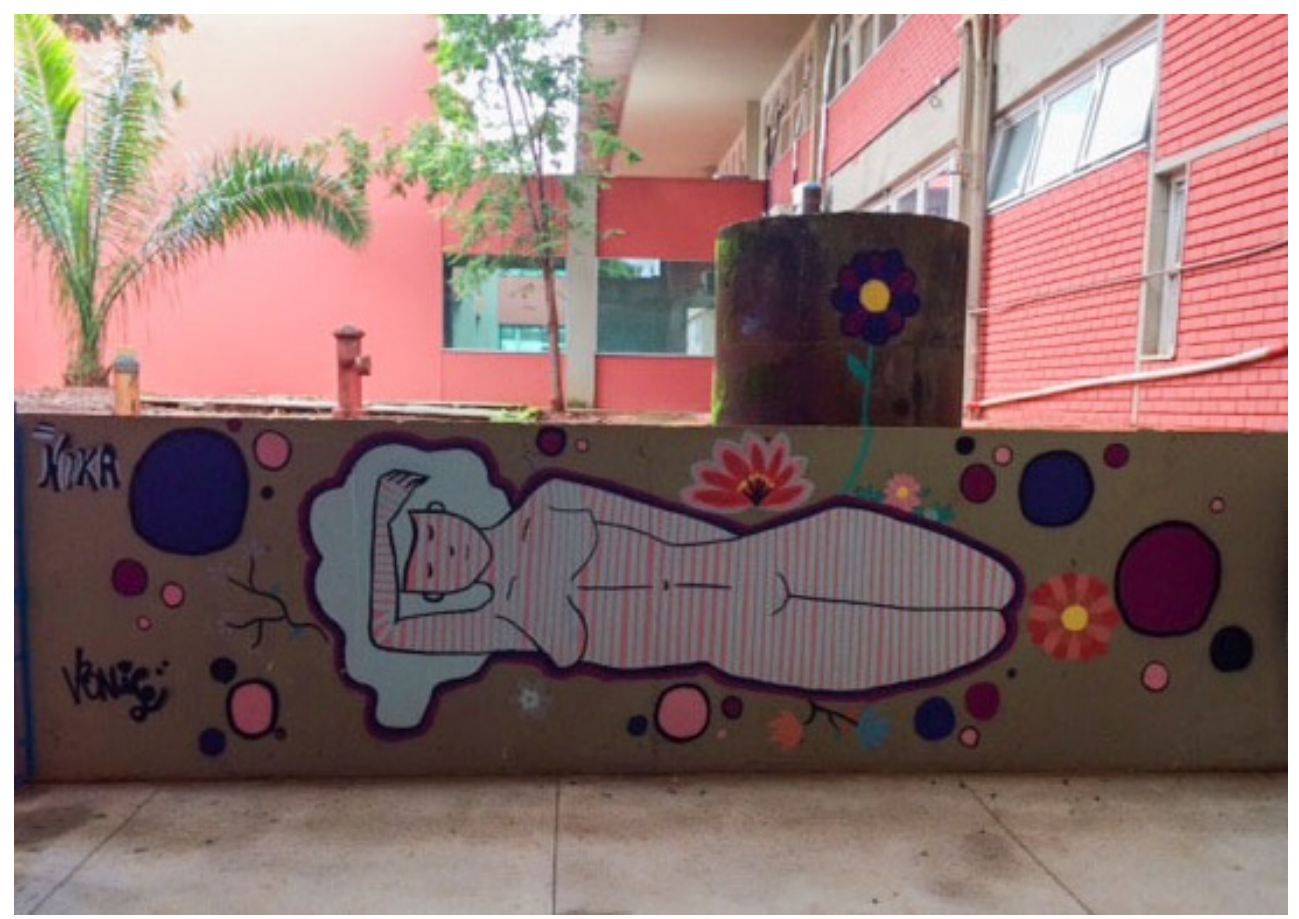

FOTO: LUCAS CASLÚ, GOIÂNIA, 2018.

No seu entendimento, Nika concebe o grafite como "arte feita nos muros da cidade, geralmente de cunho político, tendo por foco, principalmente, as desigualdades sociais". Para ela, os temas e os recursos da linguagem em 
grafite "são bem amplos, com a utilização de materiais como tinta spray, tinta líquida, pincel, rolinho, fita/cantões e stencil."

Iniciou com o grafite por volta dos 15 anos de idade, em uma atividade que aconteceu na comunidade católica no bairro Santa Genoveva. Depois disso, só teve contato no final do ano de 2017, em um curso de iniciação da técnica. Com a realização do projeto, ela retomou a atividade com o grafite. $\mathrm{Na}$ sua avaliação, a participação no projeto "proporcionou a oportunidade de praticar e me arriscar nesse estilo de arte, que não é fácil e exige muita dedicação."

\section{Lucas Fernando Rodrigues de Souza (Lucas Caslú)}

Lucas também é estudante do curso de Artes Visuais - Bacharelado, é iniciante e demonstra seu interesse pelo grafite. Nos trouxe uma forma diferenciada no trabalho que apresentou no Pátio, não utilizou o spray, desenhou livremente com o pincel, um traço livre e expressivo. Seus personagens apresentam olhos grandes, esbugalhados, com um olhar atento para ver e compreender o espaço; estes se colocam também como observadores dos passantes que transitam pelo Pátio (Figura 2).

Ficura 2 - Fotografia do trabalho de grafite de Lucas Caslu no Pátio Humanidades/ UFG.

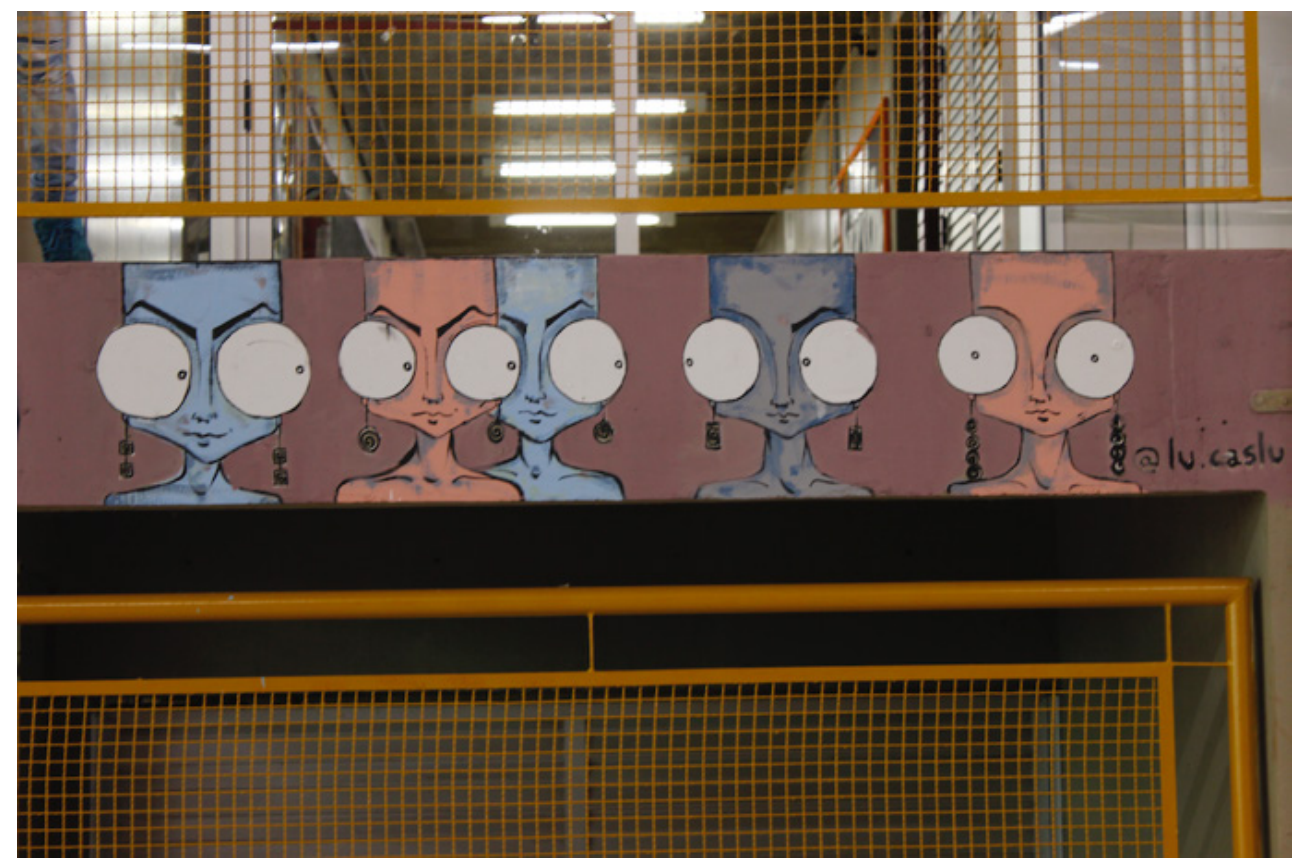

FOTO: LUCAS CASLÚ, GOIÂNIA, 2018. 


\section{Renan Accioly}

Estudante do curso de Artes Visuais - Bacharelado, Renan já tem um domínio da técnica do stencil que utiliza para desenvolver seus trabalhos. No Pátio, desenvolveu personagens do contexto brasileiro e cultura pop, valorizando a diversidade de referências culturais e sociais existentes no Brasil (Figura 3). Em sua concepção, o grafite tem um sentido amplo e conflitante, devendo receber uma atenção menos preconceituosa. Conforme sua explicação:

Percebo a relação do público com o grafite bastante conflitante. Pois não é somente a estética de trabalho que está em jogo. A pichação também é elemento fundamental do grafite e acaba sempre taxada como uma arte menor ou vandalismo. Dentro desse mesmo contexto, o público costuma identificar grafite apenas como elemento visual com grande apelo estético, que possui elementos visuais exagerados, com alto contraste de cor e figuras de destaque. O que também considero um grande equívoco, pois qualquer rabisco ou desenho realizado em parede é grafite. Então dentro desse espaço de criação, todo tipo de arte é válida e deve ser respeitada, indiferente se é de seu gosto particular ou não.

Renan iniciou o trabalho com grafite por volta de 2011, realizando intervenções artísticas em diversos espaços da cidade. Segundo ele,

[...] a partir de telas feitas em stencil, saía pelas ruas de Goiânia espalhando diversos tipos de intervenções. Comecei com reproduções de desenhos e artes de protesto, principalmente de temática punk e de resistência. Nesta mesma época também produzi camisetas realizadas com técnica de stencil e depois acabei me focando na minha primeira graduação com jornalismo, deixando tudo isso um pouco de lado. Apenas quando iniciei a graduação em Artes comecei a repensar essa proposta, estabelecendo novos critérios para meus trabalhos, procurando aprofundamento e desdobramentos dessa técnica. 
Ficura 3 - Fotografia do trabalho de grafite de Renan Accioly no Pátio Humanidades/ UFG.

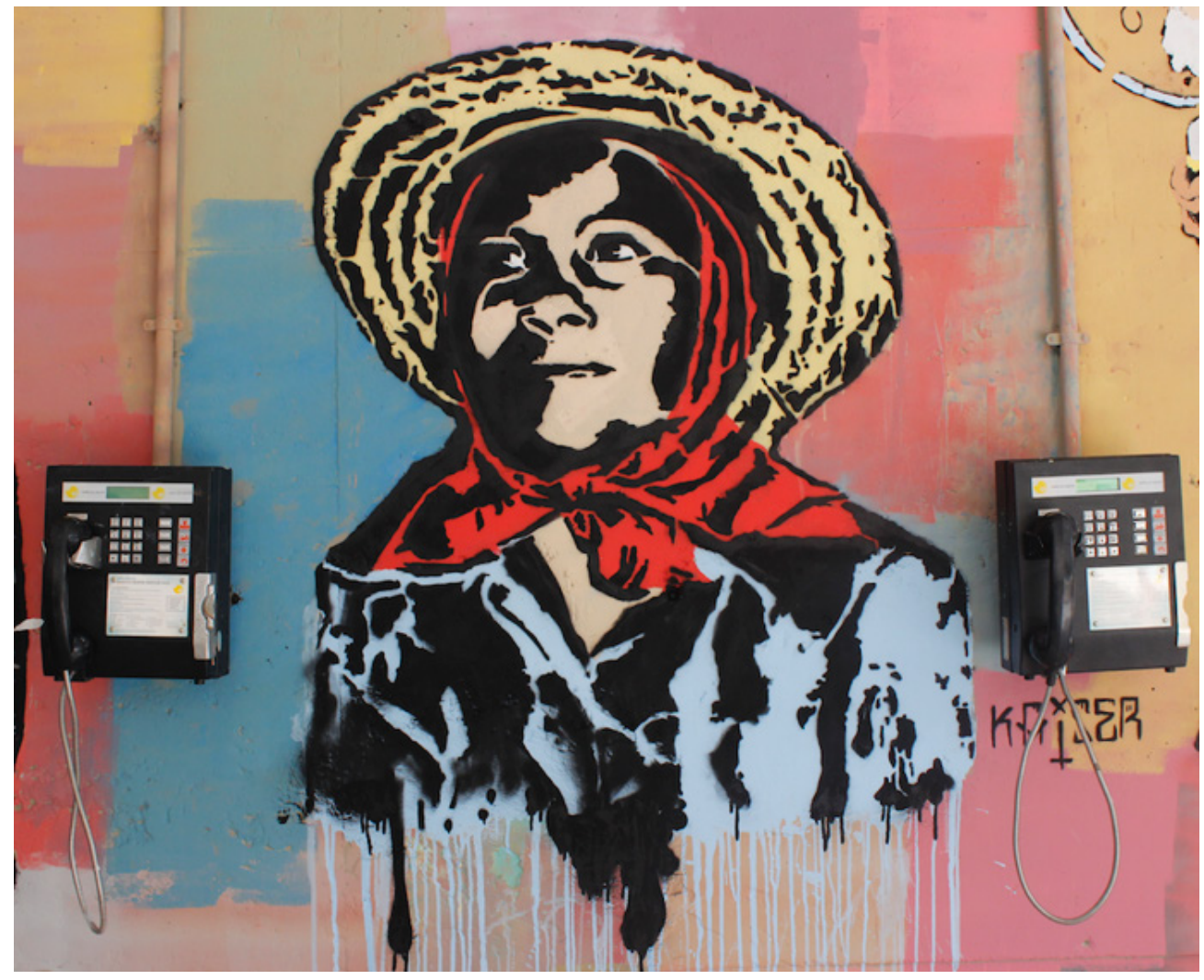

FOTO: LUCAS CASLÚ, GOIÂNIA, 2018.

Jhony Robson dos Santos (Bulacha)

Artista visual atuante, egresso do curso de Artes Visuais - Bacharelado, anteriormente ao seu ingresso na UFG, já fazia grafites nas ruas de Goiânia e em outras cidades que visitou. Conhecido no meio artístico como Bulacha, é considerado um multi-artista, pois atua também como palhaço, malabares e na construção de brinquedos populares.

Seu trabalho tem como objetivo apresentar questões sociais e questionar o cidadão. Suas imagens carregam indagações, com a intencionalidade de propor por meio da arte transformações sociais (Figura 4). Considera que o grafite é uma ferramenta de transformação, que comunica em diferentes lugares. Para ele, o grafite é uma

linguagem na qual eu atinjo muitas pessoas de forma inesperada, tanto que quanto eu estou na rua fazendo grafite, as pessoas me perguntam, porque é que eu faço?; qual a ideia 
daquilo?; porque eu faço aquilo daquela forma?; então eu acho que [o grafite] é uma ferramenta instigante, que aproxima pessoas mais diversas do mundo.

Em seu depoimento, fala do seu início com o grafite:

Como na maioria dos grafiteiros, eu vim da pixação. Eu pixava aí nos anos de 1992, e de 94 a 98 . Em 98 comecei a pintar os primeiros grafites no bairro onde eu morava, na Vila Coronel Cosme, na invasão. A partir disso eu me interessei bastante, depois de muitos anos, eu fui participar de um encontro, que funcionava no Centro de Goiânia, na Assessoria da Juventude, que era regido pela União do Movimento Hip Hop organizado de Goiás. Era um movimento organizado e neste lugar também tinha oficinas de grafite, que foi onde eu aprimorei as técnicas, passei a pintar em diversos eventos dentro do movimento Hip Hop e, depois de muitos anos, eu entrei na Universidade. [...] e na Universidade, eu tive a possibilidade de desdobrar melhor o meu trabalho de grafiteiro, me apropriando de um estilo, que hoje eu trabalho muito com o gesto contínuo, que é uma das coisas que eu desenvolvo mais dentro do meu trabalho e aprendi a trabalhar com cores.

Ficura 4 - Fotografia do trabalho de grafite de Bulacha no Pátio Humanidades/UFG.

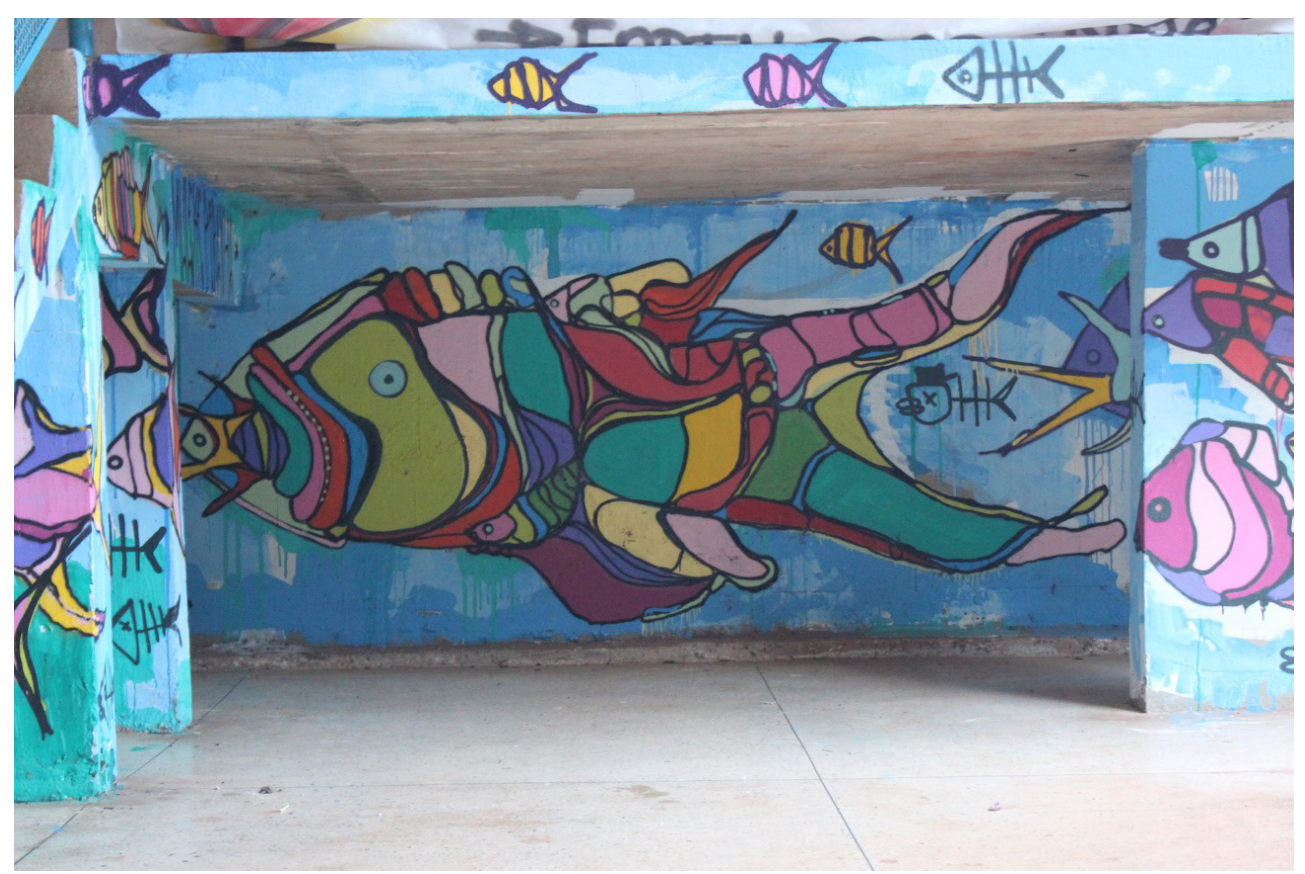

FOTO: LUCAS CASLÚ, GOIÂNIA, 2018.

Diogo Fernandes Honorato (Rustoff)

Artista visual egresso da UFG, realizou o curso de Artes Visuais - Design Gráfico na FAV. Desde o ano de 2006 trabalha com o grafite. Faz uso de vários 
recursos expressivos, em especial, com a técnica do stencil. Sua temática gira em torno de personagens do "nosso" cotidiano, apresenta figuras jovens, numa relação da imagem e o local onde ela será instalada a obra. Realiza um pensar sobre o espaço não ocupado, de uma parede, de um elemento arquitetônico, e a partir do experienciar esse espaço ele insere as suas imagens (Figura 5).

Rustoff considera polêmica a definição do termo grafite - para a qual, ele utiliza a expressão de origem italiana, graffiti. No seu entendimento, a arte do grafite

[...] geralmente é uma arte pública, um desenho, um nome escrito com uma letra estilizada só com a assinatura do grafiteiro. Pode ser feita com ou sem permissão, em muros públicos ou privados. Eu utilizo da tradição do graffiti e da técnica do stencil para realizar meus trabalhos de forma pública. Fazendo com que eles se integrem à paisagem urbana.

Sobre seu início com a técnica do grafite, Rustoff reitera:

Iniciei em 2006, coincidentemente no mesmo ano que ingressei no Curso de Design Gráfico da FAV/UFG. Eu tinha uma noção sobre graffiti, acompanhava por revistas e via algumas coisas pelas ruas. Mas em 2006, através da internet, eu conheci o trabalho de artistas que usavam o stencil para fazer seus trabalhos. Me identifiquei de imediato, pois era uma estética que me agradava muito. Comecei a fazer nas ruas de Goiânia apenas por diversão até que a prática evoluiu de maneira natural. Desde então, me mantenho envolvido na produção e pesquisas em streetart, pintura e gravura.

Ficura 5 - Fotografia do trabalho de grafite de Rustoff no Pátio Humanidades/UFG.

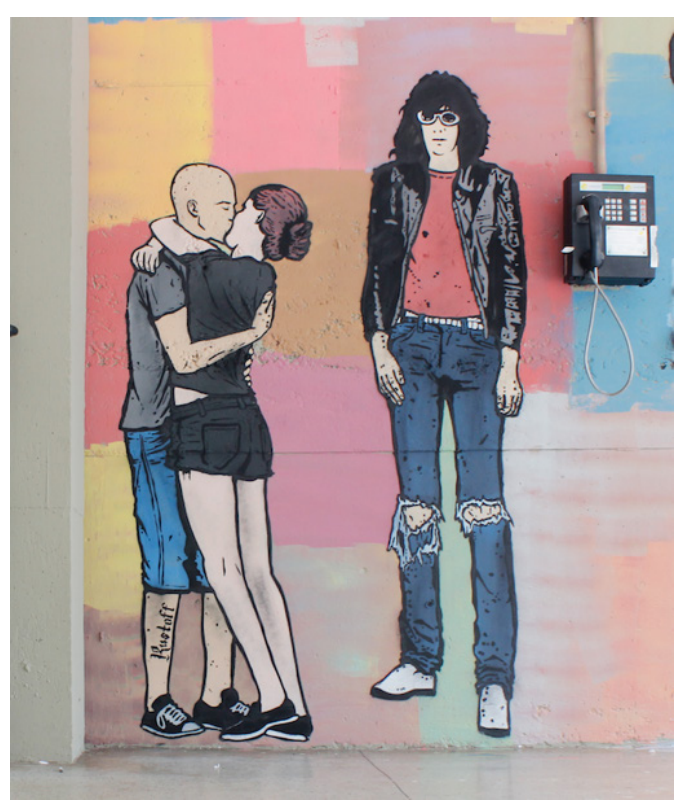

FOTO: LUCAS CASLÚ, GOIÂNIA, 2018. 


\section{Pirandello (Vladimir Martins da Silva)}

Artista visual autodidata, Pirandelo reside no bairro Itatiaia e participa do projeto "Por uma poética compartilhada" na UFG. Seu trabalho em grafite pode ser apreciado em vários locais na região próximo à universidade. Tem um interessante trabalho em pintura em tela e outras técnicas artísticas. Ao longo de sua carreira, sempre valorizando a experimentação como processo de aprendizagem, realizou várias exposições e recebeu alguns prêmios em salões regionais. Há alguns anos leva a sua experiência para o grafite, demonstrando um domínio fabuloso no trato da pintura. Sua atitude cuidadosa e detalhista, faz com que o olhar do espectador adentre no seu universo imaginário de histórias e cores em estilo surrealista (Figura 6).

Segundo o artista, o fato de ter nascido num contexto familiar de baixa renda, com vários irmãos, desde a infância a inventividade, a imaginação e as atividades lúdicas faziam parte do seu cotidiano. A liberdade na participação em brincadeiras de rua e as leituras frequentes das histórias em quadrinhos foram marcantes no seu processo de formação artística.

Já no colégio, eu tinha facilidade para o desenho [...]. Na classe [da escola], também, eu tinha uma facilidade de fazer as capas de trabalho, aquelas letras estilizadas, todo mundo queria que eu fizesse as capas. Eu sempre tive facilidade para o desenho [...]. Mas eu só fui começar a ganhar algum dinheiro, a comercializar algum trabalho, quando eu tava lá por volta dos quinze anos, que comecei a pintar camisetas e comecei a vender. [...] Gostava de pintar influenciado por capas de rock de disco de vinil. Pintava também algumas inspirações em revistas, eu gostava de temas como disco voador, outros planetas, achava que isso desenvolvia uma figura legal. Eu desenvolvi uma técnica [...] comprei uma peneirinha de plástico, passava a tinta assim e soprava, fazia um fundo, aqueles fundos cósmicos com aquelas cores... e vinha com aquelas paisagens bem futuristas. [...] Eu levava então as camisetas na feira hippie na avenida Goiás, fazia um varal, e comecei a fazer um público de gente que gostava das camisetas mais diferenciadas. [...] E, aí, as pessoas começaram a incentivar a pintar tela. 
FicURA 6 - Fotografia do trabalho de grafite de Pirandello no Pátio Humanidades/UFG.

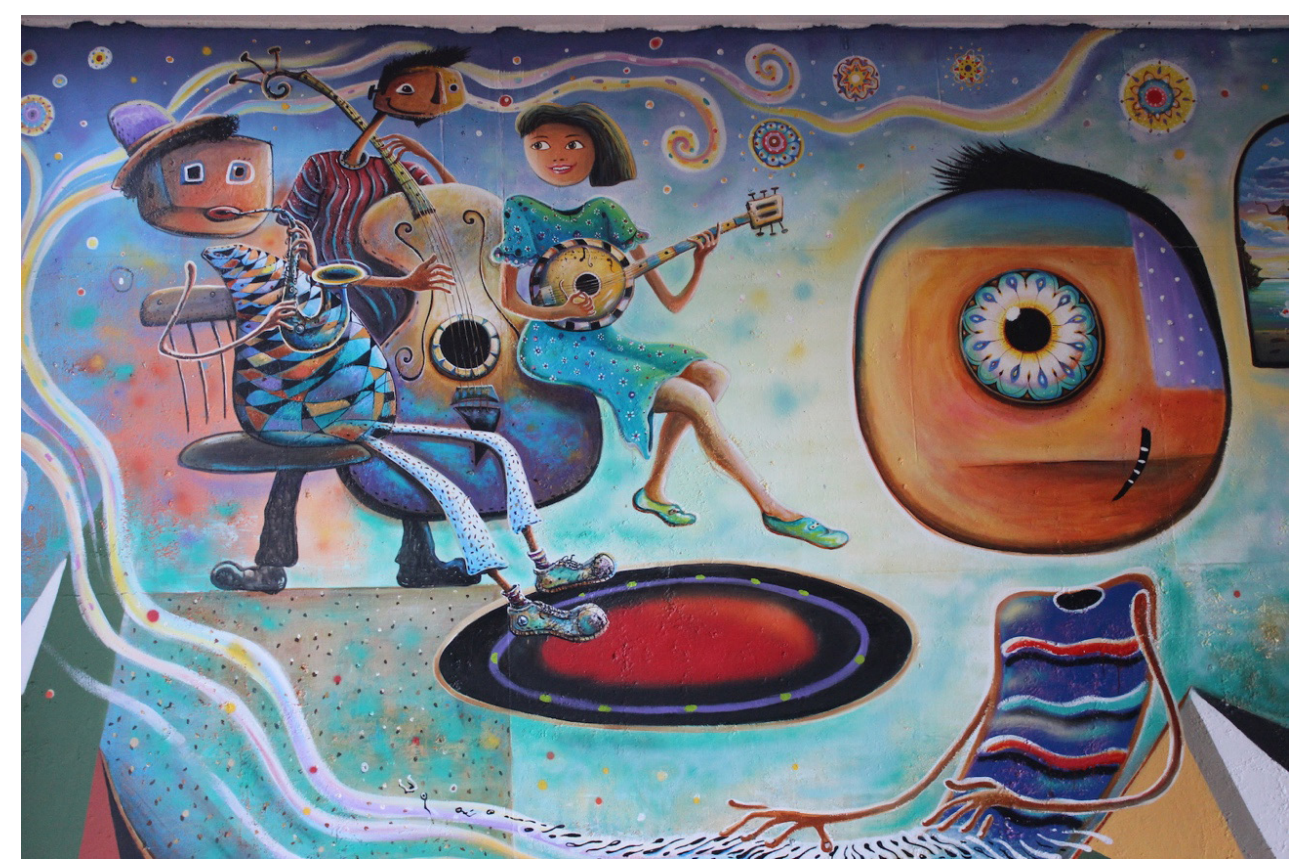

FOTO: LUCAS CASLÚ, GOIÂNIA, 2018.

\section{Ismael Albertino}

Artista visual autodidata, reside no bairro Itatiaia, é também participante do projeto "Por uma poética compartilhada". Ismael desenvolve seu trabalho com a intenção de levar o espectador para uma dimensão espiritual, por meio das formas abstratas, de linhas retas e orgânicas que inventa. Ele conduz suas pinceladas intuitivamente, porém com uma percepção espacial muito aguçada e inquieta (Figura 7). Sobre o seu processo criativo, assim afirma:

[...] procuro sempre me manter contemplativo com relação ao espaço e quem nele convive. Pinto intuitivamente numa fruição de formas e cores. Já o macaco, quis fazer uma reflexão sobre o habitat, seus primeiros habitantes e a estrutura física e pessoal do prédio da faculdade [na UFG], que é por onde transitam em busca de alimentos e etc. Numa relação diversa e tal, usei a figura de um macaco mais velho (fazendo referência aos anciões que ainda resistem à corrupção) e o resultado foi de um "macaco tribal leão de fogo".

É esclarecedor e instigante o depoimento de Ismael em relação à sua formação e o seu interesse pela arte: 
Eu lembro que sempre gostava de ficar com meus primos [...] Indo para casa dos meus tios, querendo a companhia dos primos mais velhos nas férias [...] eles colecionavam gibis. Meu tio Manuel era sempre frequente nessa coisa de acompanhar e incentivá-los na leitura, e dos gibis [...]. Eu lia de tudo do Wald Disney, e ali eu pirava em toda a coleção [...]. Que eu moleque, que eu lia, mas dava muito mais atenção para os gráficos, o visual $[\ldots]$ a textura do papel [...] os efeitos, a grafia.

Depois dos primeiros fundamentos dos gibis, eu fui vendo mais desenhos na TV. [...] Passou um pouco, na escola, eu tive um primeiro contato com a rappa que escrevia os muros, os apelidos, isso já era uma coisa de autoafirmação de um sobre o outro, as tag, as assinaturas, [...] isso já era uma ação marginal, solta na escola, com canetinha e caneta. O primeiro contato que tive com essa cultura [do grafite] na escola, foi nos banheiros, com a rapaziada que lançou a coisa do territorialismo, do marginal. [...] No ensino médio [...] foi quando tive as primeiras visualizações de tipografias de escrita em árvore [...] e perceber esses maiores com a essas escritas.

Ficura 7 - Fotografia - detalhes do trabalho de grafite de Ismael Albertino no Pátio Humanidades/UFG.

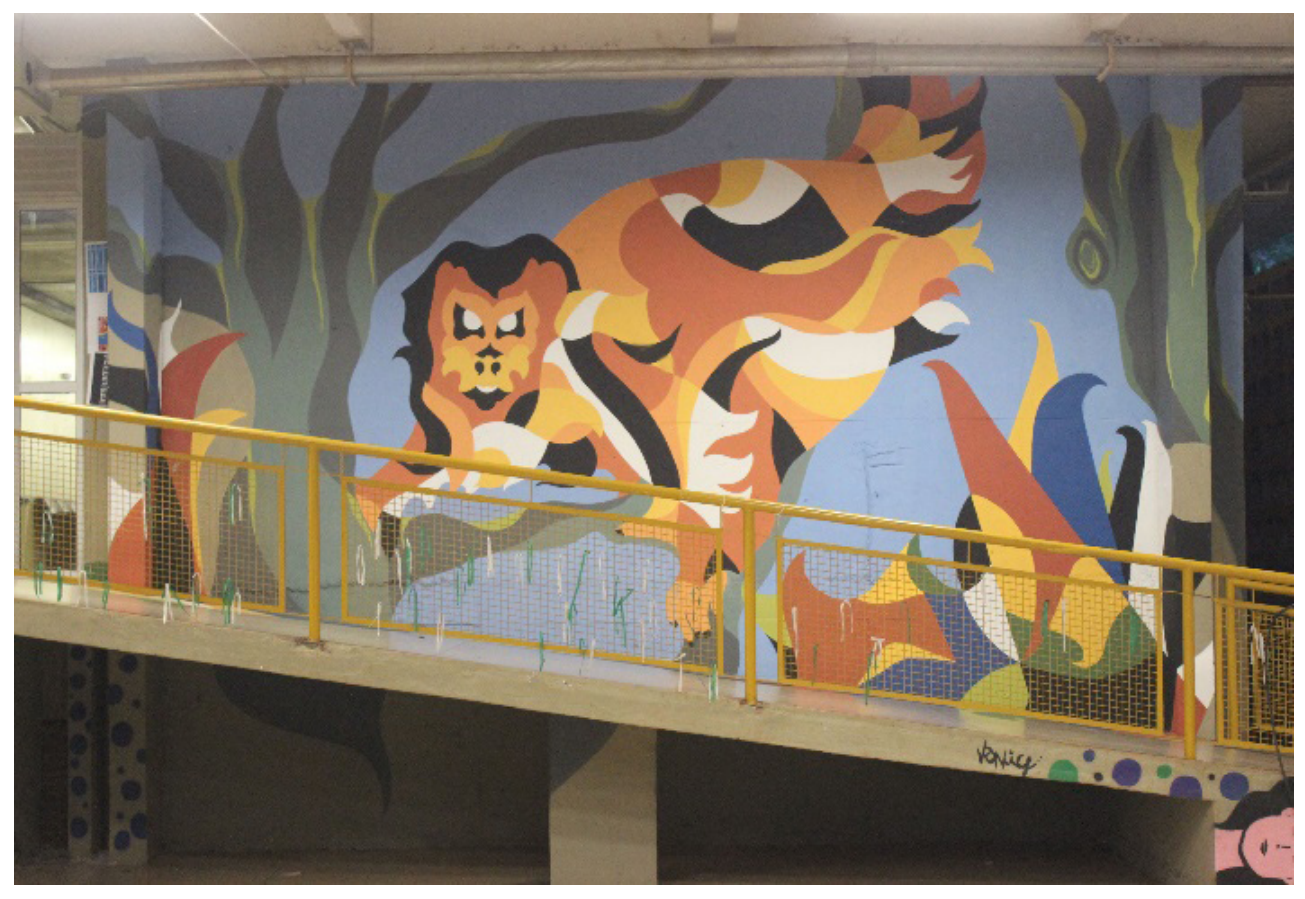

FOTO: LUCAS CASLÚ, GoIÂNIA, 2018. 


\section{Processos artísticos COMPARTILHAdOS: PERCEPÇÕES E DESAFios}

Várias paredes do Pátio Humanidades foram disponibilizadas para o projeto. Em uma visita do grupo de artistas no espaço, decidiu-se como seria feita a produção artística e os recursos necessários para a realização dos trabalhos. Conforme os interesses individuais, cada artista analisou e definiu um espaço para a concretização do seu grafite, em alguns casos, essa produção ocorreu de maneira conjunta, inter-relacionando espaços, temas e estilos artísticos.

Bulacha, com traços contínuos e cores primárias, desenvolveu seu grafite enfatizando imagens figurativas, frases e ditos populares. No seu grafite, que sobressai a figura do peixe, o artista escolheu um espaço pouco percebido, situado debaixo da rampa do prédio da História. Um aspecto importante de sua concepção artística está relacionado com a busca de "lugares esquecidos". Esses espaços, que são ressignificados pelos artistas, passam a ser possíveis de experiências estéticas. Sua concepção tem por referência as questões sociais, as quais, são assim explicitadas por ele:

[...] porque eu não pintei num lugar onde as pessoas vão para lá para ficar olhando, eu pintei num lugar que é característica do meu trabalho. São lugares esquecidos, né! São lugares que eu posso puxar para lá um novo olhar. Então eu acho que esta é uma das maiores importâncias de ter voltado na Universidade para desenvolver um trabalho que tenha um diálogo com aquele local. [...] porque antes lá aconteciam outras coisas, dentro desta questão do tráfico de drogas e tal. E dentro deste trabalho eu coloquei várias influências, vários dizeres dessas pessoas que ocupam este espaço. Também pintei naquele lugar lá uma história, né! Porque são peixes engolindo outros peixes, retratando isto como uma sociedade, né! Então, no caso, tem um escafandrista que tá fotografando tudo e mandando aquelas mensagens para um aparelho de televisão. E a televisão tá mostrando uma outra realidade para as pessoas que estão recebendo aquela informação. É isto que está escrito naquela mensagem, naquele grafite, por isso eu acho muito importante me comunicar com esta ferramenta.

Já no processo de trabalho de Nika, há um planejamento do desenho do grafite que será executado. Esclarece a artista:

O meu processo de trabalho começa com o planejamento do que eu quero fazer na parede, e por que quero trabalhar com tal temática, depois passo para o esboço, vou desenhando até chegar no que mais gosto, aí vem uma das partes mais difíceis para mim que é a escolha das cores. Quando termino esse processo inicial, me volto para a parede e começo a esboçar o desenho na parede com giz de quadro mesmo; depois que esboço, passo para as camadas de tinta; a primeira camada é o fundo do desenho intercalando as 
cores de acordo com o planejado, quando isso está pronto passo para o acabamento que é os detalhes do desenho, os contornos, sombras e etc.

Rustoff, na elaboração de seu trabalho, atento ao lugar em que inserirá o grafite, se coloca como um colecionador de imagens, selecionando o que vê em seu cotidiano e de leituras que faz. A partir destas coletas, constrói seus personagens com a técnica do stencil, uma técnica de pintura que se utiliza de moldes vazados, artesanalmente construídos, destinados à demarcação das pinturas. Quanto ao seu retorno à UFG, após quase 8 anos, ele disse que foi interessante realizar este trabalho:

Pude ver de perto os posicionamentos e demandas dos estudantes e da própria universidade sobre o graffiti e o ponto de vista deles sobre o espaço público. Também foi bom o intercâmbio com os outros artistas que participaram do projeto [...]. Além de achar excelente a iniciativa da instituição de manter próximo de si ex-alunos e a comunidade, e no meu caso, podendo contribuir para a construção de um bom espaço de convivência.

Já Nika e Lucas, fizeram desta participação no projeto um momento de aprendizagem, ao conviverem com os artistas egressos e os artistas do bairro, os quais conhecem, dominam e têm experiência com a técnica do grafite. Nika assim apontou:

O mais legal de conviver com artistas que possuem mais experiência, é conhecer um pouco de suas histórias, aprender um pouco sobre os seus estilos e técnicas. É uma troca e trocas são sempre bem fundas no meio artístico. E o mais importante, aprender a conviver com o outro, esse outro que é diferente de você, mas que tem algo em comum e que se sabe ser paciente é humilde aprenderá muitas coisas que lhe farão crescer em sua arte...O que levo de positivo deste projeto, foi com certeza o aprendizado, o primeiro e mais importante ao meu ver, foi aprender a trabalhar em equipe, lidar com o outro, com as diferenças. (2018)

Podemos observar nos depoimentos que as vivências e as trocas de experiências aconteceram e foram importantes para os participantes. O estar junto, o compartilhamento, constituiu um modo de agir coletivo, que favoreceu aos artistas a abertura e a receptividade às novas possibilidade de fazer arte.

Na realização do projeto artístico no Pátio Humanidades da UFG, alguns aspectos significativos sobressaíram no decorrer do processo. Constatamos que os artistas demandaram roteiros, materiais, técnicas, tempos e espaços diferentes de execução. Cada artista apresentou uma concepção e um modo particular de conduzir o seu trabalho artístico. O respeito à autonomia dos 
artistas e à diversidade dos processos criativos dos participantes foi uma constante. Observamos que uns desenvolvem o desenho do grafite que será executado posteriormente, outros pensam sobre a relação entre o contexto e a imagem para então proceder a realização de suas propostas, alguns já trabalham o desenho do grafite diretamente na parede, sem um planejamento prévio. Notamos, também, que o processo criativo não se rotula, não segue normas ou padrão, cada qual desenvolveu seu trabalho a partir do seu modo de fazer e sua inventividade. Tal processo coaduna com o entendimento de Pareyson (2001, p. 25-26): "A arte não é somente executar, produzir, realizar, e o simples 'fazer' não basta para definir sua essência. A arte é também invenção. Ela é um tal fazer que, enquanto faz, inventa o por fazer e o modo de fazer.”

A realização dessa ação permite-nos afirmar que por meio da arte podemos desenvolver diversas maneiras de aproximação entre os indivíduos, favorecendo reflexões que extrapolam o campo artístico e estético. Avaliamos positivamente o desenvolvimento desse projeto, vinculado ao programa Topofilias, o qual deve ser ampliado na universidade, dando continuidade ao seu sentido de afetividade entre as pessoas e seus lugares.

\section{REFERÊNCIAS}

BANKSY. Guerra e spray. Rio de Janeiro: Intrínseca, 2012.

BOURRIAUD, Nicolas. Estética Relacional. São Paulo: Martins, 2009.

FARIAS, Sálvio Juliano Peixoto. Galeria Aberta: uma história por múltiplos atores. 2005. 265f. Dissertação (Programa de Pós-Graduação em Cultura Visual - Mestrado). Faculdade de Artes Visuais, Universidade Federal de Goiás, Goiânia, 2005.

FRADE, Isabela. Acervo - experiências afetivas e materialidades do lugar. In: CIRILLO, José; KINCELER, José Luiz; OLIVEIRA, Luiz Sérgio de (org.). Outro ponto de vista: práticas colaborativas na arte contemporânea. Vitória: PROEX/UFES, 2015. pp. 79-94

GANZ, Nicholas. O mundo do grafite. Arte urbana dos cinco continentes. São Paulo: Martins Fontes, 2008.

KNAUSS, Paulo. Grafite Urbano Contemporâneo. TORRES, Sônia (org). Raízes e rumos: perspectivas interdisciplinares em estudos americanos. Rio de Janeiro: 7 Letras, 2001. pp. 334-353.

LONGMAN, Eduardo. Grafite: labirintos do olhar. São Paulo: BEI Comunicações, 2017.

MILLIET, Maria Alice. Lygia Clark: obra-trajeto. São Paulo: EDUSP, 1992.

PAREYSON, Luigi. Os problemas da estética. São Paulo: Martins Fontes, 2001. 
TAVARES, Jordana Falcão. Construções, desconstruções e reconstruções: histórias do grafite goianiense contemporâneo. 2010. 171f. Dissertação (Programa de Pós-Gradução em Cultura Visual - Mestrado) Faculdade de Artes Visuais, Universidade Federal de Goiás, Goiânia, 2010.

Recebido em setembro de 2018

Aprovado em novembro de 2018 